\title{
Publisher Correction: Towards quantitative and multiplexed in vivo functional cancer genomics
}

Ian P. Winters (D), Christopher W. Murray and Monte M. Winslow

Nature Reviews Genetics (2018) https://doi.org/10.1038/s41576-018-0053-7

Published online 28 September 2018

The originally published article failed to acknowledge the equal first authorship contribution of I. P. Winters and C. W. Murray. The article has now been corrected online. The editors apologize for this error.

https://doi.org/10.1038/s41576-018-0062-6 I Published online 16 October 2018

\section{Publisher Correction: Base editing: precision chemistry on the genome and transcriptome of living cells}

\section{Holly A. Rees and David R. Liu}

Nature Reviews Genetics (2018) https://doi.org/10.1038/s41576-018-0059-1

Published online 15 October 2018

The originally published article contained errors in reference numbering throughout table 1 (DNA base editors and their approximate editing windows) due to the unintended propagation of reference numbering from an earlier version of the table. The article has now been corrected online. The editors apologize for this error.

https://doi.org/10.1038/s41576-018-0068-0 I Published online 19 October 2018 